\title{
Development and Persistence of Limbic Epileptogenesis Are Impaired in Mice Lacking Progesterone Receptors
}

\author{
Doodipala Samba Reddy and Ashwin Mohan \\ Department of Neuroscience and Experimental Therapeutics, College of Medicine, Texas A\&M Health Science Center, College Station, Texas 77843
}

\begin{abstract}
Progesterone plays a key role in ovarian cycle-related synaptic plasticity and neuronal excitability. Progesterone receptors (PRs), which mediate the cellular actions of progesterone, are expressed in the hippocampus and other limbic regions, but their functional significance remains unknown. Here, we report a novel role of PRs as crucial mediators in the development of epileptogenesis, which is the process whereby a normal brain becomes progressively epileptic because of precipitating factors. The PR knock-out $\left(\mathrm{PR}^{-I-}\right)$ mouse, which lacks both the PR-A and PR-B isoforms, exhibited an increased resistance to epileptogenesis in the hippocampus and amygdala kindling models. Lack of PRs markedly impaired the persistence of seizure expression at 4 weeks after kindling development. We further show that selective inhibition of PRs in the brain by antisense oligos or pharmacological blockade of PRs by RU-486 [11 $\beta$-[ $p$-(dimethylamino)phenyl]-17 $\beta$-hydroxy-17-(1-propynyl)estra4,9-dien-3-one] resulted in a significant decrease in epileptogenesis in wild-type $\left(\mathrm{PR}^{+/+}\right)$mice. The delayed epileptogenesis in PR knock-out mice was not substantially affected by inhibition of neurosteroid synthesis. Mice lacking PRs show supersensitivity to the antiseizure responses of progesterone. Collectively, these results suggest that PRs in the hippocampus are linked to signaling pathways that control susceptibility to epileptogenesis and possibly persistence of an epileptic-like state. The PR pathway may represent a unique target for preventing or retarding epileptogenesis in females.
\end{abstract}

\section{Introduction}

Epilepsy is a chronic condition characterized by recurrent unprovoked seizures. Presently, there is no specific drug for preventing or curing epilepsy (Jacobs et al., 2009). The mechanisms underlying the development of acquired epilepsy are not very well understood. The term "epileptogenesis" is used to describe the complex plastic changes in the brain that, after a precipitating event, convert a normal brain into a brain debilitated by recurrent seizures (Pitkänen et al., 2009). Limbic epilepsy is caused by diverse precipitating factors such as brain injury, stroke, infections, or prolonged seizures. William Gowers (1881) proposed that "seizures beget seizures." The kindling model has provided a conceptual framework for this idea and for developing new molecular targets for preventing epilepsy (Goddard et al., 1969; McNamara et al., 1992). Kindling is the most widely used model of epileptogenesis in which repeated stimulation, subthreshold for motor seizures, of limbic structures triggers progressive intensification of behavioral and electrographic seizure activity and, therefore, shares many features with human complex partial seizures (Löscher, 2002). The fully kindled state allows studying its persistence weeks or months after development. Earlier studies

Received Aug. 26, 2010; revised Nov. 2, 2010; accepted Nov. 3, 2010.

This work was supported by National Institutes of Health Grant NS051398 (D.S.R.). We thank Bert O'Malley, Michael Rogawski, Leslie Morrow, and Jean Harry for helpful feedback on PRs and 0. Gangisetty for technica support.

Correspondence should be addressed to Dr. Doodipala Samba Reddy, Department of Neuroscience and Experimental Therapeutics, College of Medicine, Texas A\&M University Health Science Center, 228 Reynolds Medical Building, College Station, TX 77843-1114. E-mail: reddy@medicine.tamhsc.edu.

DOI:10.1523/JNEUROSCI.4488-10.2011

Copyright $\odot 2011$ the authors $\quad 0270-6474 / 11 / 310650-09 \$ 15.00 / 0$ with mirror foci illustrate the same principle for epileptogenesis in humans (Morrell and deToledo-Morrell, 1999).

Progesterone $(\mathrm{P})$ has antiseizure properties and plays an important role in epilepsy. Women with epilepsy are prone to seizures in response to decreased levels of $\mathrm{P}$ during perimenstrual periods (Herzog et al., 1997; Reddy, 2009). However, the molecular mechanism of action of $\mathrm{P}$ in seizure activity is not fully understood. The cellular actions of $\mathrm{P}$ are mediated by the progesterone receptor (PR), a member of the nuclear receptor superfamily of transcription factors (Li and O'Malley, 2003). The PR exists in two isoforms, PR-A and PR-B, that are transcribed from the same gene but perform distinct cellular functions (MulacJericevic et al., 2000; Conneely et al., 2002). PRs are expressed in the brain with high levels in the hypothalamus and moderate levels in the limbic areas (Parsons et al., 1982; Auger and De Vries, 2002). PRs are widely distributed in the hippocampus (Kato et al., 1994; Alves et al., 2000; Brinton et al., 2008), but their physiological significance remains unclear. The seizure protection of $\mathrm{P}$ is undiminished in PR knock-out (PRKO) mice and occurs mainly by its conversion to $5 \alpha$-pregnane- $3 \alpha$-ol-20-one [allopregnanolone (AP)], a neurosteroid modulator of $\mathrm{GABA}_{\mathrm{A}}$ receptors (Reddy et al., 2004). Therefore, $P$ and neurosteroids may regulate neuronal plasticity and seizure susceptibility (Herzog et al., 1997; Reddy et al., 2001; Maguire and Mody, 2009). However, the functional importance of PRs in mechanisms that underlie seizure susceptibility is poorly understood. We hypothesize that $\mathrm{P}$ regulation of seizure susceptibility occurs via activation of PRs in the hippocampus, a region associated with limbic epilepsy that has both PR subtypes.

In the present study, we investigated the role of PRs in limbic epileptogenesis and tested the above hypothesis in the kindling paradigm with multiple approaches for the intervention of the PR 
pathway. Our results suggest that mice with a targeted deletion of PRs or a selective knockdown of PR expression in the brain exhibit a markedly decreased propensity for the development and persistence of kindling epileptogenesis, indicating a crucial role of PRs in seizure susceptibility.

\section{Materials and Methods}

Animals. Adult female mice (3-5 months of age) weighing $\sim 25-30$ g were used in the study. The generation of PRKO $\left(\mathrm{PR}^{-1-}\right)$ and heterozygous $\left(\mathrm{PR}^{+/-}\right)$mice by a PR-null mutation has been described previously (Lydon et al., 1995; Reddy et al., 2004). PRKO mice lack both the PR-A and PR-B isoforms that are transcribed by the PR gene. These mice were maintained in a hybrid C57BL/6129SV background. The mice were housed in an environmentally controlled animal facility under a $12 \mathrm{~h}$ light/dark cycle and allowed ad libitum access to food and water, except during the experimental sessions. Genotype was confirmed by PCR using mouse tail genomic DNA (Reddy et al., 2005a). The constitutive PRKO mice grow normally to adulthood with the exception of some reproductive abnormalities because of the lack of PRs (Lydon et al., 1995; Chappell et al., 1997, 1999). In addition to the PRKO mouse model, we used two other approaches for the intervention of the PR pathway: (1) PR antisense oligonucleotides in wild-type (WT) $\left(\mathrm{PR}^{+/+}\right)$ mice and (2) the PR antagonist $11 \beta$-[ $p$-(dimethylamino)phenyl]-17 $\beta$ hydroxy-17-(1-propynyl)estra-4,9-dien-3-one (RU-486) in WT mice. All procedures were performed in strict compliance with the National Institutes of Health Guide for the Care and Use of Laboratory Animals under a protocol approved by the Institutional Animal Care and Use Committee.

Hippocampus and amygdala kindling development. The development of kindling epileptogenesis and its preservation were assessed by hippocampus or amygdala kindling (He et al., 2004; Reddy and Jian, 2010). Mice were anesthetized by an intraperitoneal injection of ketamine (100 $\mathrm{mg} / \mathrm{kg}$ ) and xylazine $(20 \mathrm{mg} / \mathrm{kg})$, and a stimulation-recording bipolar electrode (Plastics One) was stereotaxically implanted in the right basolateral nucleus of the amygdala $(1.3 \mathrm{~mm}$ posterior, $3 \mathrm{~mm}$ lateral to bregma, and $4.6 \mathrm{~mm}$ below dura) or in the right ventral hippocampus (2.9 $\mathrm{mm}$ posterior, $3.0 \mathrm{~mm}$ lateral, and $3.0 \mathrm{~mm}$ below dura) using the Franklin and Paxinos (1997) atlas. The electrode was anchored with dental acrylic to three small screws placed in the skull. After a postoperative recovery period of at least 1 week, the electrographic seizure threshold or afterdischarge $(\mathrm{AD})$ was determined by an application of a $1 \mathrm{~s}$ train of $1 \mathrm{~ms}$ biphasic rectangular pulses at $60 \mathrm{~Hz}$, beginning at $25 \mu \mathrm{A}$. Additional stimulations increasing by $25 \mu \mathrm{A}$ were given at $5 \mathrm{~min}$ intervals until an electrographic $\mathrm{AD}$ lasting at least $5 \mathrm{~s}$ was detected using the digital EEG system (Astro-Med). Kindling stimulations (1 ms pulses, 60 $\mathrm{Hz}$ frequency, $1 \mathrm{~s}$ duration) were applied following standard protocol consisting of once-daily stimulation at $125 \%$ of $\mathrm{AD}$ threshold using an isolated pulse stimulator (A-M Systems). The day of AD determination was considered day 1 of kindling. Stimulations were delivered daily until stage 5 seizures were elicited on 3 consecutive days. The AD duration was acquired from the amygdala or hippocampal electrode using Axoscope 8.0 software (Molecular Devices). Behavioral seizures were rated according to Racine's scale (Racine, 1972), as modified for the mouse: stage 0, no response or behavior arrest; stage 1, chewing or facial twitches; stage 2, chewing and head nodding; stage 3 , forelimb clonus; stage 4, bilateral forelimb clonus and rearing; stage 5 , falling. Kindling is a permanent phenomenon and an intense seizure can be elicited weeks or months after kindling development. Four weeks after inducing stage 5 kindling, mice were tested for persistence of the kindling state by administration of an additional stimulation in a current-escalating manner until the occurrence of stage 4 or 5 seizures. Mice with electrode implanted but nonstimulated are used as sham controls.

Rapid hippocampus kindling. Rapid kindling is a model of epileptogenesis that allows accelerated evaluation of experimental manipulations during the progression of epilepsy induction (Lothman and Williamson, 1993; Sankar et al., 2010). The rapid kindling procedure was similar to the conventional kindling described above except that stimulations were applied every 30 min until mice exhibited consistent stage 5 seizures. This procedure has been used extensively as a model of compressed epilepto- genesis as an alternative paradigm to the conventional kindling models (Sankar et al., 2010).

Neurosteroid assay. Animals were anesthetized with isoflurane, and $\sim 0.5 \mathrm{ml}$ of carotid blood was collected in heparinized tubes. The plasma was separated by centrifugation at $12,000 \times g$ for $10 \mathrm{~min}$ and stored at $-20^{\circ} \mathrm{C}$. The concentration of the neurosteroid AP was analyzed by liquid chromatography-tandem mass spectrometry, as previously described (Reddy et al., 2005b). Briefly, a $0.2 \mathrm{ml}$ plasma sample was added to a tube containing evaporated internal standard. The steroid and internal standard were extracted with $4 \mathrm{ml}$ of hexane. Each sample was analyzed using the atmospheric pressure chemical ionization technique under acidic conditions. Plasma concentrations of $\mathrm{P}$ were analyzed by an immunoassay. The detection limit of the assay was $<0.2 \mathrm{ng} / \mathrm{ml}$.

$P R$ immunohistochemistry. An affinity-purified anti-PR antibody was used for immunohistochemical identification of PR expression in the brain (Mani et al., 1996; Reddy et al., 2005a). Mice were deeply anesthetized with ketamine $(100 \mathrm{mg} / \mathrm{kg})$ and xylazine $(20 \mathrm{mg} / \mathrm{kg})$ mixture and perfused via the ascending aorta with $20 \mathrm{ml}$ of saline followed by $100 \mathrm{ml}$ of $0.1 \mathrm{M}$ PBS, pH 7.4, containing 4\% paraformaldehyde. The brains were removed and postfixed overnight in $4 \%$ paraformaldehyde, equilibrated for $48 \mathrm{~h}$ in $20 \%$ sucrose in PBS at $4^{\circ} \mathrm{C}$, and stored at $-75^{\circ} \mathrm{C}$. Serial cryostat sections $(30 \mu \mathrm{m})$ were cut coronally through the cerebrum containing the amygdala nuclei and the hippocampus. Every first, second, third, fourth, and fifth sections of each series of five were collected separately. The sections were incubated in PBS containing Triton X-100 and normal serum for $1 \mathrm{~h}$ and then in the PBS containing an anti-PR polyclonal antibody (Dako; $1: 500$ ) for $3 \mathrm{~d}$ at $4^{\circ} \mathrm{C}$. The immunoreaction product was then detected according to the avidin-biotin complex method (Hsu et al., 1981) using the Vector Elite kit (Vector Laboratories). After thorough washing, sections were mounted on gelatin-coated slides, dehydrated in ethanol, and cleared in xylene. The specificity of the primary antibody was checked by omission of the anti-PR antibody or omission of the secondary antibody. Nissl staining was used to visualize cells in the second set of sections. The regions were selected according to Franklin and Paxinos (1997). Bright-field images were acquired digitally on a Nikon microscope under identical optical conditions at various magnifications.

Antisense administration. PR antisense treatments were given chronically via intracerebroventricular microinfusion in the lateral ventricle in WT mice. Phosphorothioated antisense (5'-AC-TCA-TGA-GCG-GGG-ACAACA-3') oligonucleotides were used to block both PR isoforms as previously described (Mani et al., 1994). The missense oligonucleotide to PRs (5'-ACACC-GAG-ACT-CTG-GAC-GTT-3') was used as a control. Apart from a bipolar electrode in the hippocampus, a 26 gauge guide cannula (Plastics One) was stereotaxically implanted into the lateral ventricle (coordinates in $\mathrm{mm}$ from bregma: anteroposterior, -0.5 ; lateral, + 1.5; dorsoventral, -1.0 ) of mice for antisense oligos administration. After a period of at least 1 week of recovery, dual-implanted animals were subjected to kindling. HPLC purified antisense oligos (IDT) were dissolved in sterile saline. Mice received 10 nmol of antisense or missense oligos by slow intracerebroventricular infusion once daily, $\sim 20 \mathrm{~h}$ before kindling stimulations. The efficiency with which PR antisense oligos blocked expression of PRs was evaluated in Western blots $\sim 20 \mathrm{~h}$ after treatment.

Western blotting. Western blot analysis of PR expression in the hippocampus and cortex was performed using an affinity-purified rabbit polyclonal antibody that detects both PR-A and PR-B isoforms in mice (Santa Cruz). Hippocampi were homogenized in RIPA buffer (Pierce), and the extracted protein $(100 \mu \mathrm{g})$ was loaded onto $10 \%$ Tris- $\mathrm{HCl}$ gels and subjected to electrophoresis. Blots were then transferred to a polyvinylidene fluoride membrane (Bio-Rad). Membranes were blocked in 5\% nonfat milk at room temperature for $1 \mathrm{~h}$. Membranes were then incubated with a PR antibody (1:200 dilution) or a $\beta$-actin antibody (1:1000 dilution) at $4^{\circ} \mathrm{C}$ overnight. Membranes were washed and incubated with an anti-rabbit antibody (1:1000) conjugated to HRP for $1 \mathrm{~h}$. PR bands $(116 \mathrm{kDa})$ were detected using ECL reagent (PerkinElmer). $\beta$-Actin was used as internal control.

Drug treatment. In P treatment studies, P (25 mg/kg) was injected subcutaneously $30 \mathrm{~min}$ before initiation of kindling. Our preliminary studies and published reports show that this dose activates PRs and results in transcription induction (Matsui et al., 2002). In studies using 
finasteride, $\mathrm{P}$ was given $1 \mathrm{~h}$ before finasteride treatment. $\mathrm{P}(25-100 \mathrm{mg} / \mathrm{kg})$ was also tested in fully kindled mice showing stage 5 seizures. To determine the inhibition by $\mathrm{P}$ of the expression of kindled seizures, the mice underwent a $3 \mathrm{~d}$ test protocol. On day 1 , they were verified to exhibit stage 5 seizures. On day 2 , a subcutaneous $\mathrm{P}$ injection was administered $30 \mathrm{~min}$ before stimulation. On day 3 , the animals were stimulated again without $\mathrm{P}$ pretreatment. During each test session, the behavioral seizure score and the $\mathrm{AD}$ duration were recorded as indices of drug efficacy. P, finasteride (Steraloids), and other drugs were dissolved in aqueous $15 \%$ $\beta$-cyclodextrin. By itself, $\beta$-cyclodextrin at concentrations as high as $50 \%$ failed to affect kindling seizures. RU-486 (25 mg/kg, i.p.) was given $30 \mathrm{~min}$ before kindling stimulations in WT mice. $\beta$-Cyclodextrin and other reagents were procured from Sigma-Aldrich.

Data analysis. Group data were expressed as mean \pm SEM. The normal distribution of kindling data was confirmed by the KolmogorovSmirnov normality test. The Kruskal-Wallis ANOVA and Mann-Whitney $U$ test were used to analyze significant differences in seizure stages between WT and PRKO mice. Significant differences in $\mathrm{AD}$ durations between genotype and treatment groups were assessed by Student's unpaired $t$ test, repeated-measures ANOVA, or one-way ANOVA followed by Dunnett's $t$ test. Dose-response curves and their $\mathrm{ED}_{50}$ values were analyzed for significance using the Litchfield and Wilcoxon test. Differences were considered statistically significant at $p<0.05$.

\section{Results}

\section{Neuroendocrine and hippocampus} morphological characterization

To examine likely compensatory neuroendocrine changes in PRKO mice attributable to the lack of PRs, we determined baseline plasma levels of $\mathrm{P}$ and AP in PRKO mice. $\mathrm{P}$ levels between WT and PRKO mice showed no significant difference at baseline (Fig. $1 A)$ or after exogenous $\mathrm{P}(25 \mathrm{mg} / \mathrm{kg})$ administration $(3.1 \pm 0.53 \mu \mathrm{g} / \mathrm{ml}$, WT, vs $3.5 \pm 0.81 \mu \mathrm{g} / \mathrm{ml}$, PRKO mice). Baseline levels of the P-derived neurosteroid AP did not differ significantly between genotypes (Fig. $1 B$ ) but were significantly elevated to a similar extent in PRKO and WT mice after P treatment (Fig. 1C). Consistent with previous reports (Parsons et al., 1982; Kato et al., 1994), PR-immunoreactive neurons were observed in the hypothalamus, hippocampus, amygdala, and neocortex in WT mice, but PR immunoreactivity was undetectable in the brains of PRKO mice (Fig. 1D), confirming a deletion of PRs in the brain. To verify morphological changes in the PRKO mouse brain, we performed a series of cytochemical studies with Nissl-stained sections. Histological analysis revealed normal architecture of the ventral and dorsal hippocampus (Fig. $1 E, H$ ), amygdala (Fig. $1 F$ ), neocortex, and hypothalamic regions in PRKO mice. The distribution of neurons in the basolateral region of the amygdala was similar between genotypes (Fig. 1G). The pyramidal cell layers at the CA1 and CA3 subfields, and hilar and granule cells of dentate gyrus in the PRKO
B
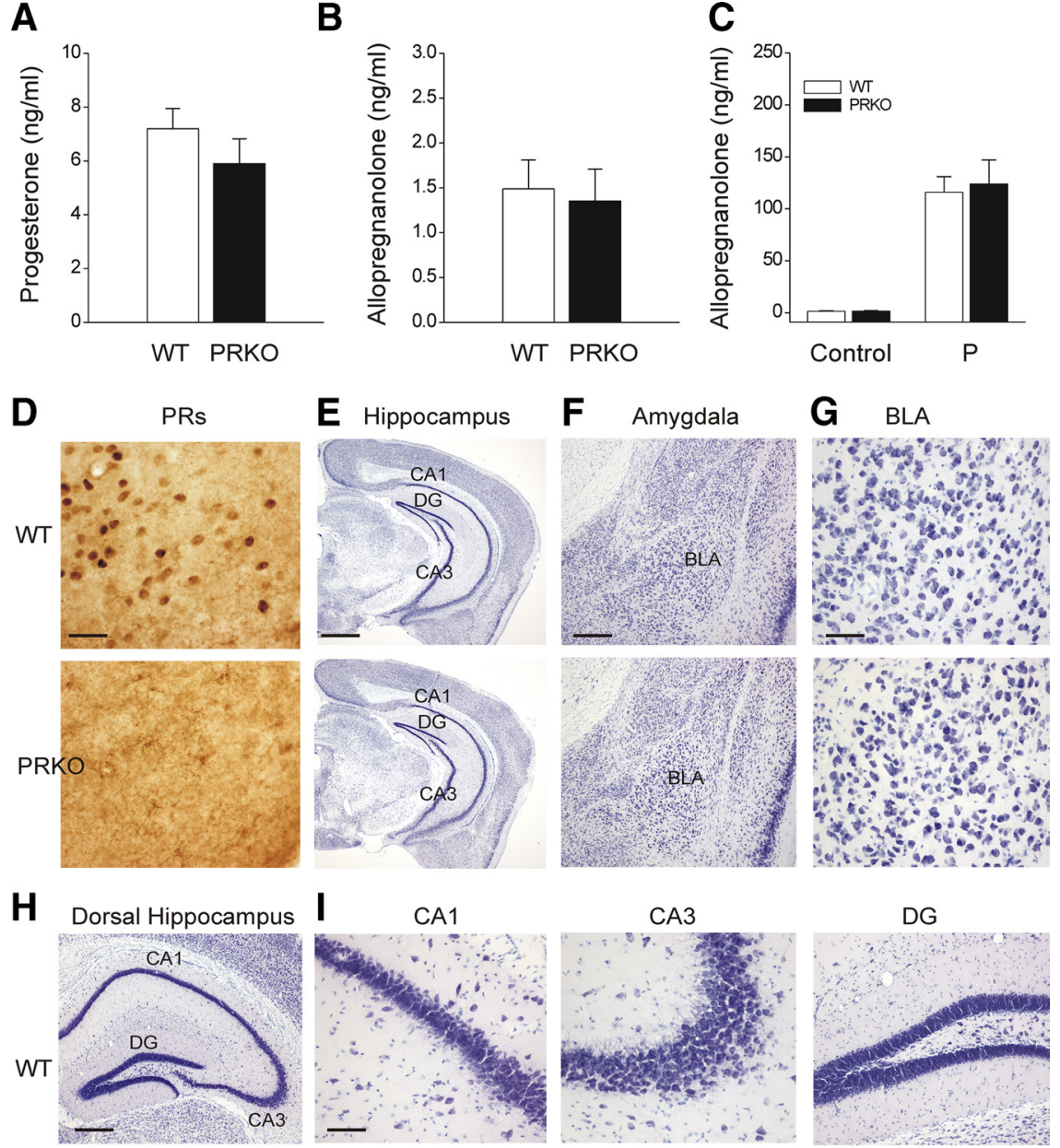
were similar between WT and PRKO mice, but AP levels were significantly elevated to a similar extent after P ( $25 \mathrm{mg} / \mathrm{kg}$, s.C.) injection (C). Data represent mean \pm SEM ( $n=8-12$ animals per group). $\boldsymbol{D}$, Lack of immunoreactive PR expression in PRKO hippocampus. $\boldsymbol{F}$, The distribution of Nissl-stained neurons in the basolateral amygdala (BLA) was similar in WT and PRKO mice. $\boldsymbol{G}$, The BLA region is enlarged to show the distribution of neurons. $\boldsymbol{H}$, The cytoarchitecture of the dorsal hippocampus is similar between genotypes. I, Nissl-stained neurons within the dorsal hippocampus CA1, CA3, and dentate gyrus (DG) regions were similar in WT and PRKO mice. Scale bars: $\boldsymbol{D}, 25 \mu \mathrm{m} ; \boldsymbol{E}, 1000 \mu \mathrm{m} ; \boldsymbol{F}, \boldsymbol{H}, 400 \mu \mathrm{m} ; \boldsymbol{G}, \boldsymbol{I}, 75 \mu \mathrm{m}$.

mouse appeared normal, and were similar to age-matched WT control (Fig. $1 H, I$ ). Thus, compensatory increases in levels of $\mathrm{P}$ or neurosteroids, and hippocampal abnormalities were not evident in PRKO mice.

\section{PRKO mice are resistant to hippocampus kindling epileptogenesis}

To determine the role of PRs in susceptibility to epileptogenesis, we studied the development and retention of hippocampus kindling in PRKO mice. The progression of electrographic AD seizures, behavioral seizures, and the rate of kindling were recorded as main indices of epileptogenesis (Fig. 2). PRKO mice showed a significant resistance to the development of kindling epileptogenesis, as evident in the increased number of stimulations re- 
A

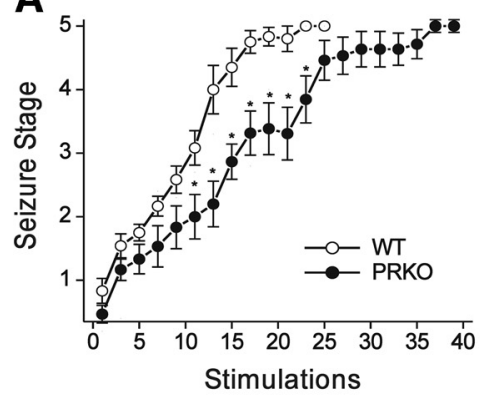

B

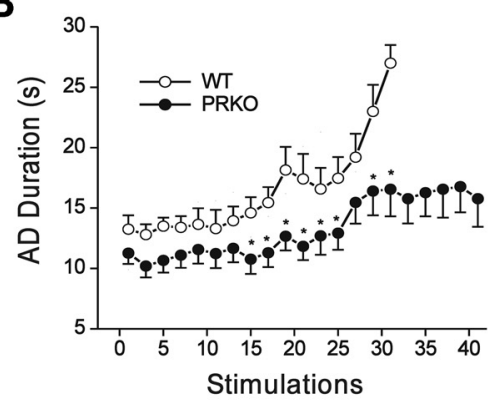

D

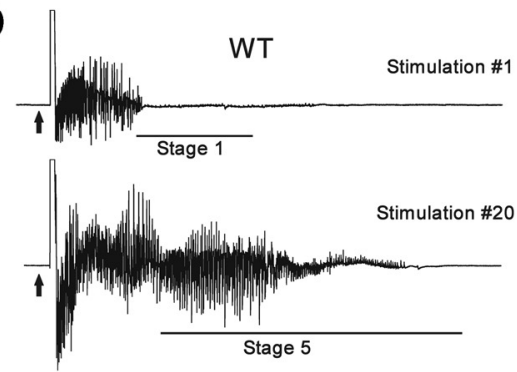

F

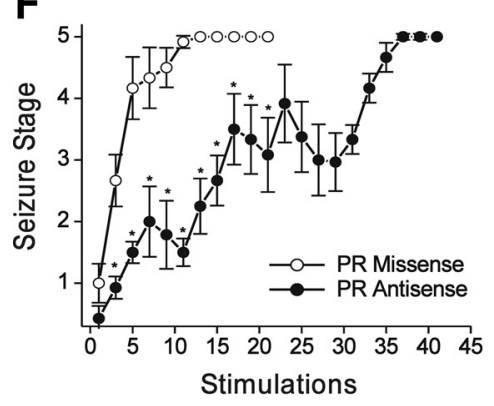

I

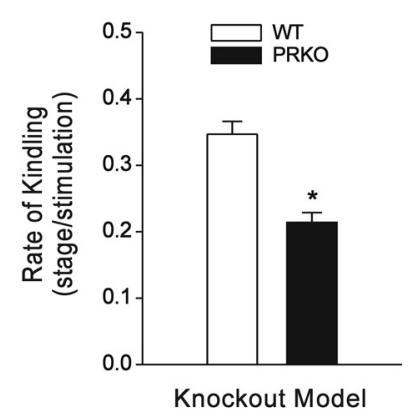

G

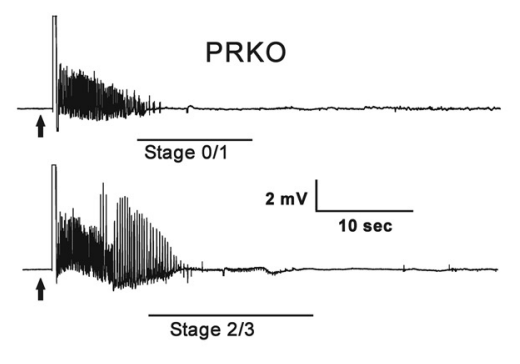

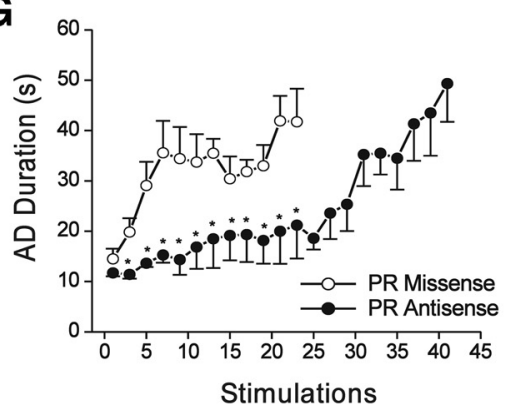

J

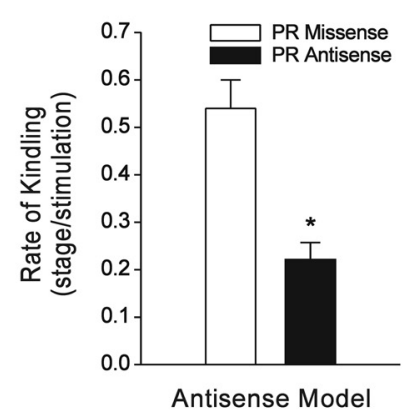

C

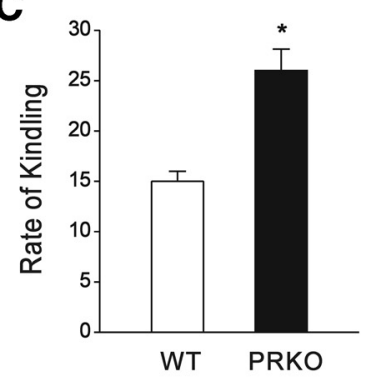

E

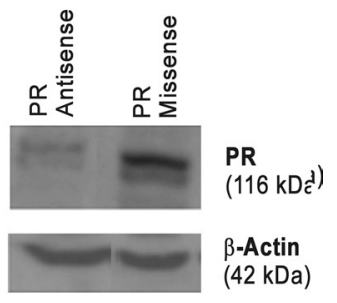

H
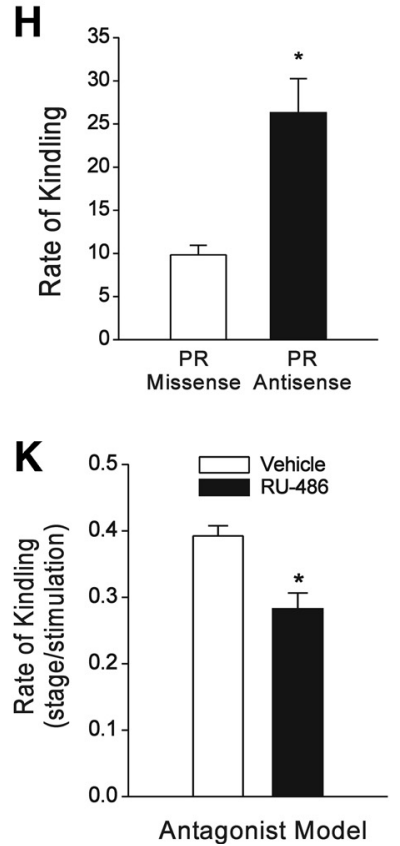

Figure 2. $\quad A-D$, Inhibition of hippocampus kindling epileptogenesis in PRKO mice. $A$, PRKO mice displayed marked retardation of kindling development as expressed by a lower mean seizure stage at the corresponding stimulation session. $\boldsymbol{B}, A$ D duration was markedly lower in PRKO than in WT mice. The single asterisks in $A$ and $\boldsymbol{B}$ indicate that the mean value is significantly $(p<0.05)$ different from that in WT control. C, Rate of kindling development (number of stimulations for stage 5 seizures) was significantly inhibited in PRKO mice. Values represent the mean \pm SEM ( $n=7-10$ mice per group). ${ }^{*} p<0.01$ versus WT control. D, Sample traces of electrographic AD seizure activity in PRKO mice during hippocampus kindling development. The traces show depth recordings from a right hippocampus stimulating-recording electrode after 1st and 20th stimulations. The arrows at the bottom indicate kindling stimulation that was followed by an artifact or a period of blanking surrounding the $1 \mathrm{sstimulus.} \mathrm{The} \mathrm{slownegative} \mathrm{wave} \mathrm{after}$ stimulation was digitally subtracted in each trace. Behavioral seizure stages are indicated on the trace. At the 20th stimulation, the WT mouse had a $37 \mathrm{sseizure} \mathrm{discharge} \mathrm{with} 31 \mathrm{sg}$ eneralized (stage 4/5) seizures, whereas the PRKO mouse had only a 17 s seizure discharge with 15 s partial (stage 2/3) seizures. $\boldsymbol{E}-\boldsymbol{H}$, Inhibition of hippocampus kindling epileptogenesis in WT mice treated with PR antisense oligos. $\boldsymbol{E}$, Western blot analysis of PR expression in the hippocampus. Representative immunoblots of PR and $\beta$-actin in WT mice treated with PR missense or antisense oligonucleotides. Hippocampus tissues were isolated $\sim 20$ h after intracerebroventricular infusion of $10 \mathrm{nmol}$ of PR antisense or missense oligonucleotides in WT mice. $\boldsymbol{F}$, WT mice treated with PR antisense oligos displayed a striking retardation of kindling development as expressed by a lower mean seizure stage at the corresponding stimulation session. $\boldsymbol{G}, \mathrm{AD}$ duration was markedly lower in the PR antisense group. The single asterisks in $\boldsymbol{F}$ and $\boldsymbol{G}$ indicate that the mean value is significantly $(p<0.05$ ) different from that in missense control. $\boldsymbol{H}$, Rate of kindling development (number of stimulations for stage 5 seizures) was significantly inhibited in antisense-treated WT mice. Values represent the mean \pm SEM ( $n=7-10$ mice per group). ${ }^{*} p<0.01$ versus missense control. $\boldsymbol{I}-\boldsymbol{K}$, Comparison of the rate of hippocampus kindling epileptogenesis in three models of PR intervention: PRK0 mouse model $(\boldsymbol{I})$, PR antisense model $(\boldsymbol{J})$, and the PR antagonist RU-486 model $(\boldsymbol{K})$. Mean seizure stage values were fit to the linear function $S n=R n+A$, where $S n$ is the mean seizure stage for the $n$th stimulation, $R$ is the rate of kindling, and $A$ is set equal to zero in all three approaches. Values represent the mean $\pm S E M .{ }^{*} p<0.05$ versus control group.

quired to elicit behavioral seizures compared with WT controls (Fig. 2A). Measures of evoked electrographic characteristics revealed a significant inhibition of AD duration in PRKO mice (Fig. $2 B, D)$. As shown in Figure $2 C$, the rate of kindling, expressed as the number of stimulations required to induce stage 5 seizures, was significantly inhibited in PRKO mice $(26 \pm 2.2)$ compared with WT mice $(15 \pm 1.1)$, with intermediate effects evident in heterozygous littermates $(22 \pm 1.4)$. The mean number of stim- 
Table 1. Mean number of stimulations to achieve hippocampus kindling stages in PRKO mouse model and the PR antisense model in WT mice

\begin{tabular}{lrrlll}
\hline \multirow{2}{*}{$\begin{array}{l}\text { Seizure } \\
\text { stage }\end{array}$} & \multicolumn{2}{l}{ PRK0 mouse model } & & \multicolumn{2}{l}{ PR antisense model } \\
\cline { 2 - 3 } \cline { 5 - 6 } \cline { 5 - 6 } & \multicolumn{1}{c}{ WT } & PRK0 & & Missense & Antisense \\
\hline Stage 1 & $1.8 \pm 0.29$ & $2.6 \pm 0.31$ & & $1.5 \pm 0.22$ & $2.34 \pm 0.61$ \\
Stage 2 & $3.34 \pm 0.46$ & $8.7 \pm 1.17^{*}$ & & $2.7 \pm 0.34$ & $9.7 \pm 1.26^{* *}$ \\
Stage 3 & $8.5 \pm 0.61$ & $14.6 \pm 1.52^{*}$ & & $4.0 \pm 0.73$ & $21.7 \pm 2.47^{* *}$ \\
Stage 4 & $11.6 \pm 0.69$ & $19.3 \pm 1.05^{*}$ & & $6.7 \pm 0.67$ & $24.8 \pm 2.93^{* *}$ \\
Stage 5 & $15.0 \pm 1.07$ & $25.4 \pm 2.14^{*}$ & & $9.8 \pm 1.04$ & $26.3 \pm 3.95^{* *}$ \\
\hline
\end{tabular}

Values represent mean \pm SEM of number of stimulation values derived from the experiments in Figure $2, A$ and $F$. ${ }^{*} p<0.05$ versus WT control; ${ }^{* *} p<0.05$ versus missense control.

ulations required to achieve various seizure stages was significantly delayed in PRKO mice (Table 1). The duration of the initial AD was similar in WT and PRKO animals at $14 \pm 2$ and $11 \pm 2 \mathrm{~s}$, respectively (Fig. $2 \mathrm{D}$ ). No significant differences in the current that was required to trigger the initial $\mathrm{AD}$ were evident between genotypes $(85 \pm 10,89 \pm 11$, and $95 \pm 13 \mu \mathrm{A}$ in WT, heterozygous, and PRKO mice, respectively). To determine the role of PRs in the permanency of kindling epilepsy, we determined a stimulation current-response relationship in WT and PRKO mice, 4 weeks after kindling development. The threshold current needed to evoke stage $4 / 5$ seizures in PRKO mice (366 \pm $22 \mu \mathrm{A})$ was significantly higher than in WT controls $(131 \pm 25$ $\mu \mathrm{A})$. Thus, mice lacking PRs are relatively resistant to hippocampus epileptogenesis and impaired in its retention.

\section{Antisense knockdown of PRs in WT mice decreases epileptogenesis}

To further confirm the role of PRs in epileptogenesis, we used PR antisense oligos for selective inhibition of PRs in WT mice. There was an almost complete ( $\sim 95 \%)$ knockdown of PR protein expression in the hippocampus $\sim 20 \mathrm{~h}$ after intracerebroventricular $(10 \mathrm{nmol})$ administration of antisense oligos in the lateral ventricle in WT mice (Fig. 2E). Behavioral and electrographic seizure progression was shown in Figure 2, F and G. PR antisense-treated WT mice showed marked resistance to development of kindling epileptogenesis compared with PR missense-treated WT controls. The rate of kindling was strikingly slower in the animals that received antisense oligos (Fig. $2 \mathrm{H}$ ). The mean number of stimulations required to achieve various seizure stages was strikingly delayed in PR antisense-treated WT mice (Table 1). No significant group differences in initial AD duration were observed. Significant increases were identified in the current required to trigger the $\mathrm{AD} \sim 20 \mathrm{~h}$ after treatment with $\mathrm{PR}$ antisense oligos in WT mice (67 \pm 13 and $190 \pm 34 \mu \mathrm{A}$ in missense and antisense groups, respectively). However, there was no change in mean threshold for expression of stage 4/5 seizures 4 weeks after kindling. In a parallel experiment, RU-486 treatment caused a seizure resistance response in WT mice, as evident from significant inhibition in the rate of kindling for inducing stage 5 seizures $(12 \pm 0.4$, vehicle, vs $18.5 \pm 1.5$, RU-486), suggesting that a blockade of PRs impairs epileptogenesis. RU-486 blocks PRs as well as glucocorticoid receptors (GRs). To compare the progression of epileptogenesis in the PRKO model with other approaches, the actual rate of kindling (seizure stage per stimulation) was calculated in the three approaches for the intervention of the PR pathway. As shown in Figure $2 I-K$, the decrease in the rate of kindling relative to that in controls was comparable in the three models. Thus, the delayed epileptogenic responses in WT mice with antisense knockdown of PRs are similar to that in PRKO mice.
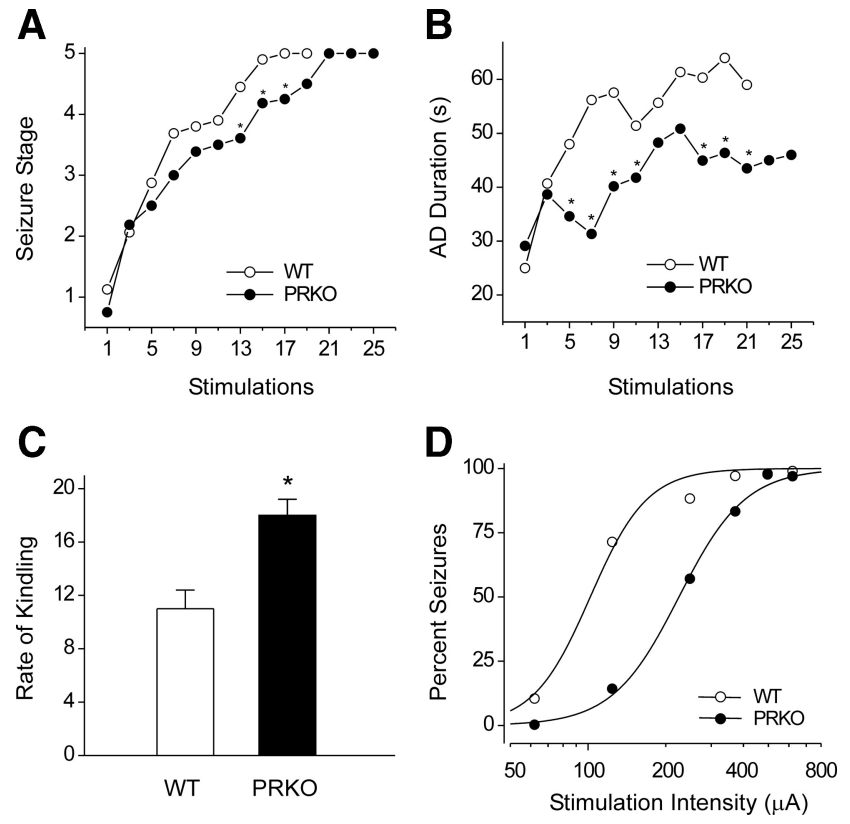

Figure 3. Increased resistance to amygdala kindling epileptogenesis in PRKO mice. A, PRKO mice displayed marked retardation of kindling development, as expressed by a lower mean seizure stage at the corresponding stimulation session. $\boldsymbol{B}, A D$ duration was significantly lower in PRKO than in WT mice. The single asterisks in $\boldsymbol{A}$ and $\boldsymbol{B}$ refer to $p<0.05$ compared with WT control ( $n=8$ mice per group). $C$, Rate of kindling development for stage 5 seizures was significantly inhibited in PRKO mice. Values represent the mean $\pm \operatorname{SEM~(~} n=8$ mice per group). ${ }^{*} p<0.05$ versus WT control. $\boldsymbol{D}$, The stimulation-response curve in PRKO mice was significantly $(p<0.05)$ shifted toward the right from the WT control as assessed by the percentage of animals exhibiting stage $4 / 5$ seizures evoked by various current intensities when examined at 4 weeks after kindling development ( $n=8$ mice per group).

\section{PRKO mice exhibit resistance to amygdala kindling epileptogenesis}

To ascertain whether kindling deficits were specific to the hippocampus or also occur in other limbic structures, we performed amygdala kindling in PRKO mice. PRKO mice showed marked suppression of the development of behavioral seizures (Fig. $3 A$ ) and shorter AD duration (Fig. $3 B$ ) than WT controls. As illustrated in Figure $3 C$, the rate of kindling for achieving stage 5 seizures was significantly delayed in PRKO mice (18 \pm 1.2$)$ compared with WT mice $(11 \pm 1.4)$ and heterozygous littermates $(12.7 \pm 1.2)$. The average value of threshold current for inducing an initial AD did not differ significantly between WT $(326 \pm 32$ $\mu \mathrm{A})$ and PRKO mice $(456 \pm 44 \mu \mathrm{A})$. Kindling was maintained in both groups at 4 weeks after development. However, the threshold current for induction of stage $4 / 5$ seizures at 4 weeks after kindling development was significantly higher in PRKO (579 \pm $78 \mu \mathrm{A})$ than in WT $(289 \pm 35 \mu \mathrm{A})$ animals, and the currentresponse relationship was shifted toward the right from that of the WT controls (Fig. 3D). Thus, development and persistence of amygdala kindling epileptogenesis are markedly impaired in PRKO mice.

\section{PRKO mice exhibit reduced epileptogenic-like response in rapid kindling}

To further elucidate the role of PR mechanisms in susceptibility to epileptogenesis, we used "rapid" kindling as a model of acute epileptogenesis, which is the process of epilepsy induction by stimulation every $30 \mathrm{~min}$, rather than a once-daily stimulation in regular kindling. PRKO mice exhibited striking impairment of hippocampus epileptogenesis induced by rapid kindling (Fig. 

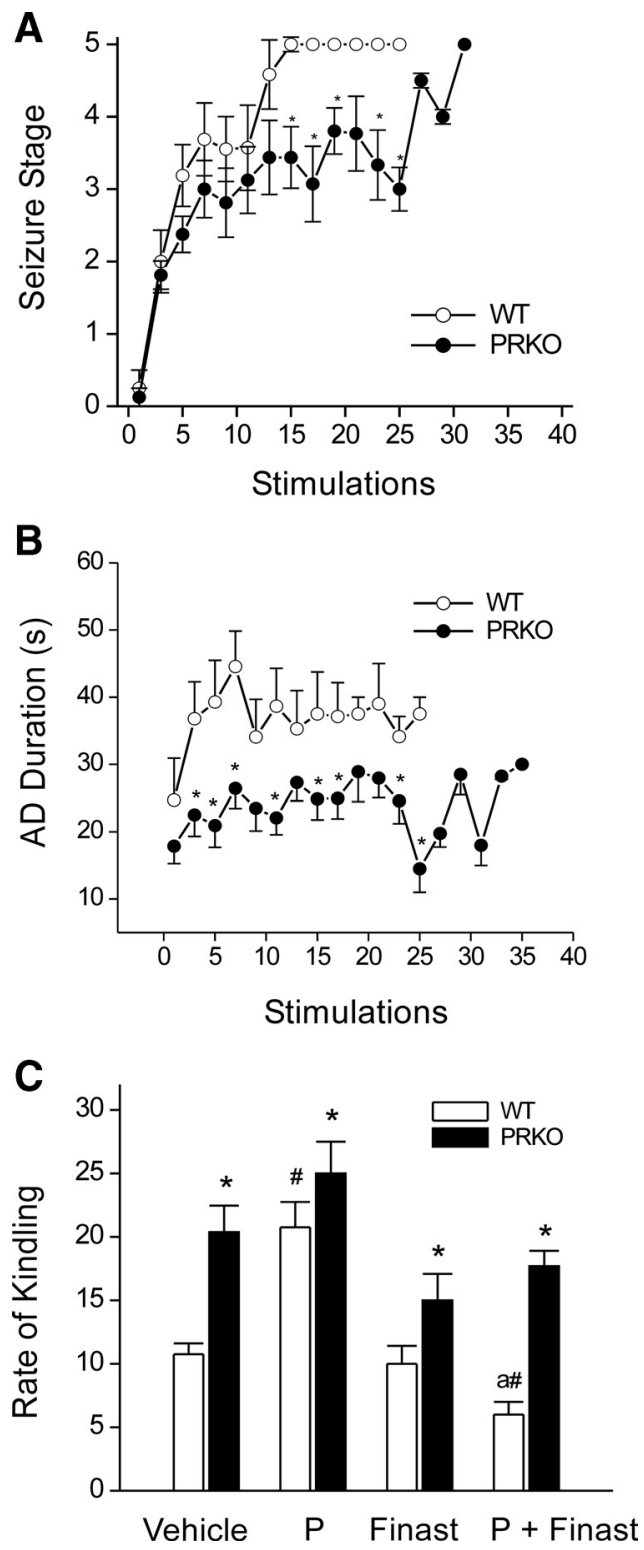

Figure 4. Role of PR and neurosteroid pathways in kindling epileptogenesis. $\boldsymbol{A}, \boldsymbol{B}, \mathrm{PRKO}$ mice displayed marked retardation of rapid hippocampus kindling development, as expressed by a lower mean seizure stage $(\boldsymbol{A})$ and electrographic AD duration $(\boldsymbol{B})$ than in WT mice at the corresponding stimulation sessions. The single asterisks in $\boldsymbol{A}$ and $\boldsymbol{B}$ refer to $p<0.05$. Values represent the mean \pm SEM ( $n=6-9$ mice per group). C, Rate of kindling development for stage 5 seizures in PRKO mice with P and/or finasteride treatment. Rate of rapid kindling for stage 5 seizures was slower in control PRKO mice. In WT mice, the inhibition by P of kindling was blocked by finasteride. $P$ ( $25 \mathrm{mg} / \mathrm{kg}$, s.c.) was given 30 min before stimulation sessions and finasteride ( $50 \mathrm{mg} / \mathrm{kg}$, i.p.) was injected $1 \mathrm{~h}$ before $P$ treatment. Values represent the mean \pm SEM ( $n=6-9$ mice per group). ${ }^{*} p<0.05$ versus WT group; ${ }^{\#} p<0.05$ versus vehicle-treated WT group; ${ }^{a} p<0.05$ versus progesterone-treated WT group.

$4 A, B)$, as evident in the significantly increased number of stimulations $(20 \pm 2)$ required to elicit stage 5 seizures compared with WT controls $(10 \pm 1)$, with intermediate effects evident in heterozygous littermates $(14 \pm 1)$ (Fig. $4 C)$. No significant differences in the current required to evoke the initial $\mathrm{AD}$ were evident between genotypes $(116 \pm 22,75 \pm 9$, and $110 \pm 23 \mu \mathrm{A}$ in WT, heterozygous, and PRKO mice, respectively). To determine the role of PRs in the retention of rapid kindling epileptogenesis, PRKO mice were tested for seizure expression 1 week after rapid kindling. The mean current threshold for evoking stage $4 / 5$ sei- zures was significantly higher in PRKO mice $(596 \pm 54 \mu \mathrm{A})$ than WT mice $(229 \pm 22 \mu \mathrm{A})$. Thus, the overall rapid kindling profile is similar and comparable with the profile of regular kindling showing PR-mediated epileptogenesis.

\section{Relative roles of PRs and neurosteroids in hippocampus epileptogenesis}

To explore mechanisms underlying the observed seizure resistance, we investigated the role of neurosteroids using finasteride, a $5 \alpha$-reductase inhibitor that blocks the synthesis of P-derived neurosteroids. We determined the rate of rapid kindling in control WT and PRKO mice, and in mice that had received injections of P $(25 \mathrm{mg} / \mathrm{kg})$ with or without concurrent finasteride $(50 \mathrm{mg} /$ $\mathrm{kg}$ ) treatment (Fig. 4C). P produced a significant delay in the rate of kindling in WT mice, compared with their control groups. Pretreatment with finasteride blocked the inhibition by $\mathrm{P}$ of kindling epileptogenesis in WT mice, but such treatment produced no significant change in the rate of kindling in PRKO mice compared with control responses or $\mathrm{P}$ treatment alone (Fig. 4C), which is consistent with a contributory role of $\mathrm{P}$-derived neurosteroids in seizure resistance in WT animals. The mean values of P-induced AP levels (WT, $116 \pm 15 ; \mathrm{PRKO}, 123 \pm 22 \mathrm{ng} / \mathrm{ml}$ ) were significantly reduced after finasteride treatment (WT, $18 \pm$ 3 ; PRKO, $22 \pm 3 \mathrm{ng} / \mathrm{ml}$ ). Thus, inhibition of neurosteroids could shift the balance, such that the activation of PRs by P could trigger mechanisms that may promote epileptogenesis.

\section{Mice lacking PRs are supersensitive to the protection by $P$ against kindled seizures}

To determine the antiseizure sensitivity of $\mathrm{P}$ in mice lacking PRs, we tested the effect of $\mathrm{P}$ in fully kindled PRKO mice. The antiseizure activity of $\mathrm{P}$ was undiminished in $\mathrm{PRKO}$ mice compared with WT controls (Fig. 5A,B). However, there was a substantial increase in the sensitivity of P in PRKO mice, as the doseresponse curve for the antiseizure effect of $\mathrm{P}$ was significantly shifted in a parallel fashion to the left from that of WT animals (Fig. $5 A, B$ ). The $\mathrm{ED}_{50}$ values of $\mathrm{P}$ suppression of seizures evoked by hippocampus kindling in WT and PRKO groups are $63 \pm 5$ and $12 \pm 2 \mathrm{mg} / \mathrm{kg}$, respectively. Moreover, the plasma levels of $\mathrm{AP}$ achieved at various doses of $\mathrm{P}$ treatment were similar between PRKO and WT mice (Fig. 5C), indicating that P sensitivity was not attributable to pharmacokinetic factors. To further extend the above findings, we also determined the sensitivity of $\mathrm{P}$ in fully kindled WT mice after inhibition of PR expression by antisense (10 nmol, i.c.v.) treatment. P caused increased inhibition of kindled seizures in WT mice treated with $\mathrm{PR}$ antisense oligos $\left(\mathrm{ED}_{50}\right.$, $11 \pm 2 \mathrm{mg} / \mathrm{kg})$ compared with missense controls $\left(\mathrm{ED}_{50}, 71 \pm 6\right.$ $\mathrm{mg} / \mathrm{kg}$ ). Moreover, the antiseizure sensitivity of $\mathrm{P}$ was found to be enhanced in WT mice treated with RU-486 ( $\left.\mathrm{ED}_{50}, 28 \pm 6 \mathrm{mg} / \mathrm{kg}\right)$, compared with their vehicle controls $\left(\mathrm{ED}_{50}, 50 \pm 15 \mathrm{mg} / \mathrm{kg}\right)$. Thus, the enhanced antiseizure effect of $\mathrm{P}$ is related to a lack of PRs in the brain.

\section{Discussion}

The present study shows that animals with a targeted deletion of PRs or a selective knockdown of PR expression in the brain are less prone to epileptogenesis. The persistence of this epileptic-like excitability condition was also impaired in mice lacking PRs. The key observations of this study are as follows: (1) PRKO mice exhibit striking impairment of development and persistence of hippocampus epileptogenesis, (2) PRKO mice exhibit marked impairment of development and persistence of amygdala epileptogenesis, (3) selective inhibition of PRs in the brain inhibits the 
A

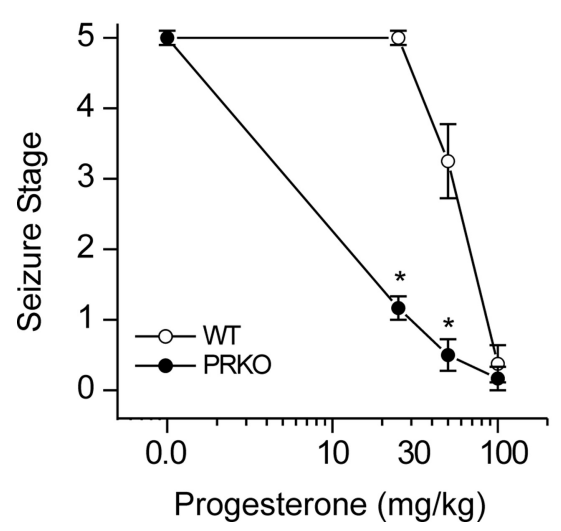

B

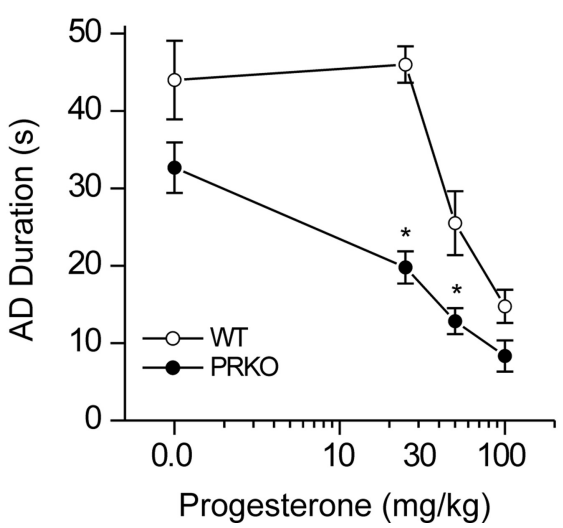

C

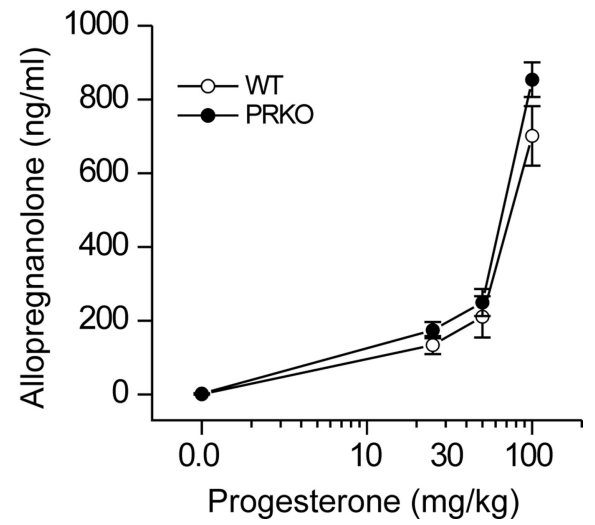

Figure 5. Increased P antiseizure sensitivity in PRKO mice. Dose-response curves for P ( $25-100 \mathrm{mg} / \mathrm{kg}$, s.c.)-induced suppression of behavioral seizure stage ( $\boldsymbol{A})$, AD duration ( $\boldsymbol{B})$, and elevation of plasma AP levels $(\boldsymbol{C})$. Mice were kindled as described in Figure $2 A$ and were tested when they had exhibited the fully kindled state. Vehicle or $P$ was injected subcutaneously 30 min before stimulation or plasma sample collection. Each point represents the mean \pm SEM ( $n=6-9$ mice per group). ${ }^{*} p<0.05$ versus WT mice.

development of hippocampus kindling in WT mice, (4) the delayed epileptogenesis in PRKO mice is not prevented by inhibition of neurosteroid synthesis, and (5) PRs mediate proconvulsant effects since $P$ exhibits supersensitivity in mice lacking PRs. Collectively, these results indicate that the PR pathway plays an important role in promoting epileptogenesis, long-term stability of this epileptic-like state, and modulating the ability of $\mathrm{P}$ to suppress seizures. However, there are certain caveats that must be considered in regards to the interpretation of these findings. First, the results apply only to the kindling models used in this study. Second, this study supports the role of PRs in limbic epileptogenesis to the extent that kindling development represents a model of epileptogenesis. The lack of antiepileptogenic efficacy of antiepileptic drugs phenytoin and carbamazepine in patients is highly consistent with studies in the kindling model (Silver et al., 1991; Löscher, 2002), supporting its validity as a model of epileptogenesis. Previous studies by Morrell and deToledo-Morrell (1999) with mirror foci as a special form of secondary epileptogenesis in humans underscore similar principles of progressive epileptogenesis.

\section{PRs affect neuronal plasticity and epileptogenesis}

Our results provide clear evidence that the induction and persistence of hippocampus and amygdala kindling are markedly disrupted in mice lacking PRs. Focal electrographic AD is required for induction of epileptogenesis in the kindling model (Goddard et al., 1969; Albertson et al., 1984). The delayed kindling development in PRKO mice is not attributable to differences in focal electrographic seizures because the duration of evoked $\mathrm{AD}$ was similar among WT and PRKO mice during the early stimulation session. However, the progressive increase in duration of the $\mathrm{AD}$ seizure activity with successive stimulations was significantly attenuated in PRKO mice. There was no significant difference in the baseline behavioral seizure activity during the early stimulation sessions. Moreover, PRKO mice respond normally to seizures induced by chemoconvulsants such as kainic acid, pilocarpine, and strychnine (Reddy and Mohan, 2010). These results indicate that the structural and functional connections that are required to exhibit behavioral and electrographic seizures are normal in the PRKO mice. Nevertheless, the plasticity that is required for transforming a normal brain to an epileptic brain in the kindling model was delayed or attenuated in the PRKO mice. Although PRs are not directly involved in the anti- seizure effects of P (Reddy et al., 2004), they appear to play a role in $\mathrm{P}$ sensitivity, because $\mathrm{P}$ had increased antiseizure potency in PRKO mice.

The present findings raise some important issues. First, because the PRKO mouse model cannot distinguish the two PR receptor isoforms (Lydon et al., 1995), it remains unclear whether the seizure susceptibility response is attributable to the PR-A or PR-B subtypes. Given that both isoforms are present in the hippocampus, future studies will determine their relative roles in seizure susceptibility. Second, the PRKO mouse model may have alterations in gene networks that provide functional compensation during the development. However, no major abnormal neuronal phenotype has been identified in mice carrying a null mutation of the PR gene other than pleotropic reproductive deficiencies (Lydon et al., 1995; Chappell et al., 1997). The delayed kindling development in PRKO mice is not attributable to compensation by PR gene network signaling in the brain because (1) the current required to evoke an $\mathrm{AD}$ was similar in the WT and PRKO mice, (2) no significant difference was noted between WT and PRKO in the duration and amplitude of the AD evoked by the first stimulation, and (3) the behavioral seizure development increased correspondingly with the steady progression of electrographic seizures in both genotypes. Moreover, kindling persistence is lower in PRKO mice. It is unlikely that this deficit is attributable to retarded kindling development because the number of stimulations required to reach the kindled state do not affect its retention (Dennison et al., 1995). In addition, antisense knockdown of PRs in the hippocampus confers inhibition of kindling development in WT mice, confirming the role of PRs in limbic epileptogenesis.

Pharmacological blockade of PRs by RU-486 is associated with inhibition of epileptogenesis. The main caveat with RU-486 is lack of specificity for selective inhibition of PRs because it also blocks GRs, which facilitate seizure activity. However, RU-486 modulation of epileptogenesis may not be related to its ability to block GRs because previous studies have demonstrated that RU486 has no effect on electrical or chemically induced seizures and amygdala-kindled seizures in animals (Mohammad et al., 1998; Borowicz et al., 2002; Persad et al., 2004), but it effectively blocks the GR agonist corticosterone facilitation of seizure activity (Talmi et al., 1995; Zhou et al., 2010). Furthermore, the RU-486 experiments were performed without any exogenous $\mathrm{P}$ administration. Therefore, there is little possibility that $\mathrm{P}$, at physiological 
levels, act on other receptors in addition to PRs that could affect seizures.

\section{$P$ regulates seizure susceptibility via PRs: pathophysiological implications}

The mechanisms underlying PR-mediated epileptogenesis remain unclear. The mechanisms involved in epileptogenesis involve an interaction of acute and delayed anatomic, molecular, and physiological events that are both complex and multifaceted (Walker et al., 2002). Neuronal injury activates diverse signaling events, such as inflammation, oxidation, apoptosis, neurogenesis, and synaptic plasticity, which eventually lead to structural and functional changes in neurons (Löscher, 2002; Pitkänen et al., 2009). These changes are eventually manifested as abnormal hyperexcitability and spontaneous seizures. PRs, as transcription factors, are most likely to regulate $\mathrm{GABA}_{\mathrm{A}}$ receptor subunit plasticity in the hippocampus (Reddy et al., 2004). PRs may promote epileptogenesis by influencing synaptic plasticity and tonic inhibition in the hippocampus dentate gyrus, which is considered a gate for the excitability loop during epileptogenesis (Edwards et al., 2000; Maguire et al., 2005). PRs undergo ligand-independent activation by certain neurotransmitters (Mani and Portillo, 2010). It is likely that such signaling mechanisms may be involved in PR-mediated seizure susceptibility.

P may modulate epileptogenesis by activation of PRs and conversion to neurosteroids, which have anticonvulsant and antiepileptogenic properties (Holmes and Weber, 1984; Kokate et al., 1999; Lonsdale and Burnham, 2003; Biagini et al., 2006; Reddy et al., 2010). This possibility is evaluated by inhibiting the synthesis of AP using the $5 \alpha$-reductase inhibitor finasteride. Inhibition of AP synthesis could shift the balance, leading to unrestrained P actions via PRs that may trigger neural events, which ultimately leads to increased epileptogenesis. Consistent with this notion, WT mice treated with finasteride showed enhanced susceptibility to epileptogenesis because of likely PR facilitation of seizure activity during the milieu of low neurosteroid levels. The resistance to epileptogenesis in PRKO mice was not completely inhibited by finasteride, providing compelling evidence that the observed differences in epileptogenesis are mediated by PRs. Moreover, neurosteroids can also modulate PRs via metabolism of analogs that bind to PRs (Rupprecht et al., 1993). Together, it is suggested that $\mathrm{P}$ regulates seizure activity through two parallel pathways: (1) binding to PRs and (2) conversion to neurosteroids such as AP. Relative seizure resistance in mice lacking PRs or finasterideinduced increase in seizure susceptibility in WT mice is consistent with such dual pathways. These mechanisms may be relevant to the pathophysiology of catamenial epilepsy (Scharfman and MacLusky, 2006; Reddy, 2009; Gangisetty and Reddy, 2010).

In conclusion, this study demonstrates that PRs play an important role in the development and persistence of limbic epileptogenesis. These findings suggest that selective functional interventions for PRs in the hippocampus may provide unique approaches to prevent epileptogenesis in females. Additional understanding of the molecular mechanisms and the gene networks regulated by PRs in the hippocampus may provide broader insights on how PRs influence neuronal excitability at developmental periods such as puberty, menstruation, and menopause.

\section{References}

Albertson TE, Joy RM, Stark LG (1984) A pharmacological study in the kindling model of epilepsy. Neuropharmacology 23:1117-1123.

Alves SE, McEwen BS, Hayashi S, Korach KS, Pfaff DW, Ogawa S (2000) Estrogen-regulated progestin receptors are found in the midbrain raphe but not hippocampus of estrogen receptor alpha (ER- $\alpha)$ gene-disrupted mice. J Comp Neurol 427:185-195.

Auger CJ, De Vries GJ (2002) Progestin receptor immunoreactivity within steroid-responsive vasopressin-immunoreactive cells in the male and female rat brain. J Neuroendocrinol 14:561-567.

Biagini G, Baldelli E, Longo D, Pradelli L, Zini I, Rogawski MA, Avoli M (2006) Endogenous neurosteroids modulate epileptogenesis in a model of temporal lobe epilepsy. Exp Neurol 201:519-524.

Borowicz KK, Luszczki J, Matuszek M, Kleinrok Z, Czuczwar SJ (2002) Effects of tamoxifen, mifepristone and cyproterone on the electroconvulsive threshold and pentetrazole-induced convulsions in mice. Pol J Pharmacol 54:103-109.

Brinton RD, Thompson RF, Foy MR, Baudry M, Wang J, Finch CE, Morgan TE, Pike CJ, Mack WJ, Stanczyk FZ, Nilsen J (2008) Progesterone receptors: form and function in brain. Front Neuroendocrinol 29:313-339.

Chappell PE, Lydon JP, Conneely OM, O’Malley BW, Levine JE (1997) Endocrine defects in mice carrying a null mutation for the progesterone receptor gene. Endocrinology 138:4147-4152.

Chappell PE, Schneider JS, Kim P, Xu M, Lydon JP, O’Malley BW, Levine JE (1999) Absence of gonadotropin surges and gonadotropin-releasing hormone self-priming in ovariectomized (OVX), estrogen (E2)-treated, progesterone receptor knockout (PRKO) mice. Endocrinology 140:3653-3658.

Conneely OM, Mulac-Jericevic B, DeMayo F, Lydon JP, O'Malley BW (2002) Reproductive functions of progesterone receptors. Recent Prog Horm Res 57:339-355.

Dennison Z, Teskey GC, Cain DP (1995) Persistence of kindling: effect of partial kindling, retention interval, kindling site, and stimulation parameters. Epilepsy Res 21:171-182.

Edwards HE, Epps T, Carlen PL, J MacLusky N (2000) Progestin receptors mediate progesterone suppression of epileptiform activity in tetanized hippocampal slices in vitro. Neuroscience 101:895-906.

Franklin KBJ, Paxinos G (1997) The mouse brain in stereotaxic coordinates. San Diego: Academic.

Gangisetty O, Reddy DS (2010) Neurosteroid withdrawal regulates GABA-A receptor $\alpha 4$-subunit expression and seizure susceptibility by activation of progesterone receptor-independent early growth response factor-3 pathway. Neuroscience 170:865-880.

Goddard GV, McIntyre DC, Leech CK (1969) A permanent change in brain function resulting from daily electrical stimulation. Exp Neurol 25:295-330.

Gowers WR (1881) Epilepsy and other chronic convulsive diseases. London: Churchill.

He XP, Kotloski R, Nef S, Luikart BW, Parada LF, McNamara JO (2004) Conditional deletion of TrkB but not BDNF prevents epileptogenesis in the kindling model. Neuron 43:31-42.

Herzog AG, Klein P, Ransil BJ (1997) Three patterns of catamenial epilepsy. Epilepsia 38:1082-1088.

Holmes GL, Weber DA (1984) The effect of progesterone on kindling: a developmental study. Brain Res 318:45-53.

Hsu SM, Raine L, Fanger H (1981) The use of antiavidin antibody and avidin-biotin-peroxidase complex in immunoperoxidase technique. Am J Clin Pathol 75:816-821.

Jacobs MP, Leblanc GG, Brooks-Kayal A, Jensen FE, Lowenstein DH, Noebels JL, Spencer DD, Swann JW (2009) Curing epilepsy: progress and future directions. Epilepsy Behav 14:438-445.

Kato J, Hirata S, Nozawa A, Yamada-Mouri N (1994) Gene expression of progesterone receptor isoforms in the rat brain. Horm Behav 28:454-463.

Kokate TG, Banks MK, Magee T, Yamaguchi S, Rogawski MA (1999) Finasteride, a $5 \alpha$-reductase inhibitor, blocks the anticonvulsant activity of progesterone in mice. J Pharmacol Exp Ther 288:679-684.

Li X, O'Malley BW (2003) Unfolding the actions of progesterone receptors. J Biol Chem 278:39261-39264.

Lonsdale D, Burnham WM (2003) The anticonvulsant effects of progesterone and $5 \alpha$-dihydroprogesterone on amygdala-kindled seizures in rats. Epilepsia 44:1494-1499.

Löscher W (2002) Animal models of epilepsy for the development of antiepileptogenic and disease-modifying drugs. A comparison of the pharmacology of kindling and post-status epilepticus models of temporal lobe epilepsy. Epilepsy Res 50:105-123.

Lothman EW, Williamson JM (1993) Rapid kindling with recurrent hippocampal seizures. Epilepsy Res 14:209-220. 
Lydon JP, DeMayo FJ, Funk CR, Mani SK, Hughes AR, Montgomery CA Jr, Shyamala G, Conneely OM, O’Malley BW (1995) Mice lacking progesterone receptor exhibit pleiotropic reproductive abnormalities. Genes Dev 9:2266-2278.

Maguire J, Mody I (2009) Steroid hormone fluctuations and $\mathrm{GABA}_{\mathrm{A}} \mathrm{R}$ plasticity. Psychoneuroendocrinology 34 [Suppl 1]:S84-S90.

Maguire JL, Stell BM, Rafizadeh M, Mody I (2005) Ovarian cycle-linked changes in $\mathrm{GABA}_{\mathrm{A}}$ receptors mediating tonic inhibition alter seizure susceptibility and anxiety. Nat Neurosci 8:797-804.

Mani S, Portillo W (2010) Activation of progesterone receptors in female reproductive behavior: interactions with neurotransmitters. Front Neuroendocrinol 31:157-171.

Mani SK, Blaustein JD, Allen JM, Law SW, O’Malley BW, Clark JH (1994) Inhibition of rat sexual behavior by antisense oligonucleotides to the progesterone receptor. Endocrinology 135:1409-1414.

Mani SK, Allen JM, Lydon JP, Mulac-Jericevic B, Blaustein JD, DeMayo FJ, Conneely O, O'Malley BW (1996) Dopamine requires the unoccupied progesterone receptor to induce sexual behavior in mice. Mol Endocrinol 10:1728-1737.

Matsui D, Sakari M, Sato T, Murayama A, Takada I, Kim M, Takeyama K, Kato S (2002) Transcriptional regulation of the mouse steroid $5 \alpha$ reductase type II gene by progesterone in brain. Nucleic Acids Res 30:1387-1393.

McNamara JO, Morrisett R, Nadler JV (1992) Recent advances in understanding mechanisms of the kindling model. Adv Neurol 57:555-560.

Mohammad S, Abolhassan A, Pourgholami MH (1998) Evaluation of the anticonvulsant profile of progesterone in male amygdala-kindled rats. Epilepsy Res 30:195-202.

Morrell F, deToledo-Morrell L (1999) From mirror focus to secondary epileptogenesis in man: an historical review. Adv Neurol 81:11-23.

Mulac-Jericevic B, Mullinax RA, DeMayo FJ, Lydon JP, Conneely OM (2000) Subgroup of reproductive functions of progesterone mediated by progesterone receptor-B isoform. Science 289:1751-1754.

Parsons B, Rainbow TC, MacLusky NJ, McEwen BS (1982) Progestin receptor levels in rat hypothalamic and limbic nuclei. J Neurosci 2:1446-1452.

Persad V, Ting Wong CG, Cortez MA, Wang YT, Snead OC 3rd (2004) Hormonal regulation of atypical absence seizures. Ann Neurol 55:353-361.

Pitkänen A, Immonen RJ, Gröhn OH, Kharatishvili I (2009) From traumatic brain injury to posttraumatic epilepsy: what animal models tell us about the process and treatment options. Epilepsia 50 [Suppl 2]:21-29.

Racine RJ (1972) Modification of seizure activity by electrical stimulation. II. Motor seizure. Electroencephalogr Clin Neurophysiol 32:281-294.
Reddy DS (2009) The role of neurosteroids in the pathophysiology and treatment of catamenial epilepsy. Epilepsy Res 85:1-30.

Reddy DS, Jian K (2010) The testosterone-derived neurosteroid androstanediol is a positive allosteric modulator of $\mathrm{GABA}_{\mathrm{A}}$ receptors. J Pharmacol Exp Ther 334:1031-1041.

Reddy DS, Mohan A (2010) Progesterone receptor-mediated seizure susceptibility in female mice. Soc Neurosci Abstr 36:255.12.

Reddy DS, Kim HY, Rogawski MA (2001) Neurosteroid withdrawal model of perimenstrual catamenial epilepsy. Epilepsia 42:328-336.

Reddy DS, Castaneda DC, O’Malley BW, Rogawski MA (2004) Anticonvulsant activity of progesterone and neurosteroids in progesterone receptor knockout mice. J Pharmacol Exp Ther 310:230-239.

Reddy DS, O'Malley BW, Rogawski MA (2005a) Anxiolytic activity of progesterone in progesterone receptor knockout mice. Neuropharmacology 48:14-24.

Reddy DS, Venkatarangan L, Chien B, Ramu K (2005b) A high-performance liquid chromatography-tandem mass spectrometry assay of the androgenic neurosteroid $3 \alpha$-androstanediol in plasma. Steroids 70:879-885.

Reddy DS, Gangisetty O, Briyal S (2010) Disease-modifying activity of progesterone in the hippocampus kindling model of epileptogenesis. Neuropharmacology 59:573-581.

Rupprecht R, Reul JM, Trapp T, van Steensel B, Wetzel C, Damm K, Zieglgänsberger W, Holsboer F (1993) Progesterone receptor-mediated effects of neuroactive steroids. Neuron 11:523-530.

Sankar R, Auvin S, Kwon YS, Pineda E, Shin D, Mazarati A (2010) Evaluation of development-specific targets for antiepileptogenic therapy using rapid kindling. Epilepsia 51 [Suppl 3]:39-42.

Scharfman HE, MacLusky NJ (2006) The influence of gonadal hormones on neuronal excitability, seizures, and epilepsy in the female. Epilepsia 47:1423-1440.

Silver JM, Shin C, McNamara JO (1991) Antiepileptogenic effects of conventional anticonvulsants in the kindling model of epilepsy. Ann Neurol 29:356-363.

Talmi M, Carlier E, Bengelloun W, Soumireu-Mourat B (1995) Synergistic action of corticosterone on kainic acid-induced electrophysiological alterations in the hippocampus. Brain Res 704:97-102.

Walker MC, White HS, Sander JW (2002) Disease modification in partial epilepsy. Brain 125:1937-1950.

Zhou QX, Mao RR, Duan TT, Tan JW, Tian M, Cao J, Xu L (2010) Stress within the postseizure time window inhibits seizure recurrence. Epilepsy Behav 18:201-206. 